\title{
PENGARUH TARIF PAJAK DAN PROBABILITAS AUDIT TERHADAP KEPATUHAN PAJAK PENGHASILAN (Studi Eksperimen Laboratorium)
}

\author{
Lintje Kalangi \\ (Email : lintje_kalangi@yahoo.com)
}

\begin{abstract}
The objective of this research is to analyze the effect of tax rates, and the probability of audit on individual income tax compliance.This research is an explanatory research, which done through laboratory experiment, to explain the casual relationships (causality) between variables. Participants of this experiment consit of 30 students Master of Accounting and Accounting Professional Program at Faculty of Economics, Sam Ratulangi University, Manado. The model analysis was of the research using Normal Censored Tobit ).The results indicate that: (1) tax rate has positive effect on tax compliance behavior. (2) probability of audit has positive effect on compliance tax and changes in probability of audit level has different effect on compliance tax.
\end{abstract}

\section{PENDAHULUAN}

Pajak merupakan sumber utama penerimaan negara dalam rangka kemandirian pembiayaan pembangunan. Penerimaan pajak meningkat secara signifikan dari tahun ke tahun. Namun demikian, kinerja penerimaan pajak tersebut belum maksimal. Permasalahan yang dihadapi Indonesia adalah kenaikan penerimaan pajak setiap tahun tidak diikuti oleh kenaikan tax ratio sesuai dengan yang diharapkan. Rasio pajak (tax ratio) Indonesia masih rendah yakni hanya 11-12\% dari produk domestic bruto (PDB). Tax ratio sebesar itu tergolong rendah. Idealnya, tax ratio bisa mencapai 15-17\% (http://www.pajak.go.id).

Perkembangan penerimaan pajak di Indonesia mengalami peningkatan yang signifikan dari tahun ke tahun. Pada tahun 2010, setiap jenis pajak meningkat berkisar tiga sampai lima kali lipat dibanding tahun 2001 sebagaimana diperlihatkan pada Gambar 1.

\section{Gambar 1}

Penerimaan Pajak Negara Periode 2001-2010 (dalam Rp juta)

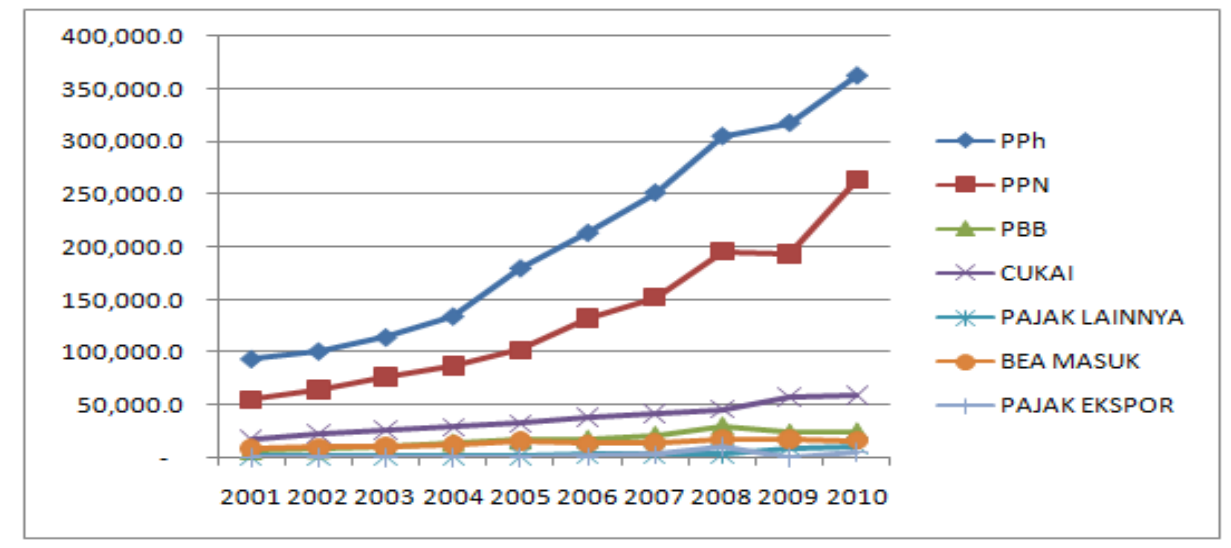

Sumber : Kementerian Keuangan Republik Indonesia (2011).

Penyumbang terbesar atas penerimaan pajak adalah pajak penghasilan $(\mathrm{PPh})$, yaitu sebesar rata-rata 50 persen dari total penerimaan pajak untuk kurun waktu yang sama (lihat Gambar 2 untuk perubahan proporsi tiap jenis pajak terhadap total penerimaan pajak). 
Gambar 2

Proporsi Penerimaan Tiap Jenis Pajak atas Total Pajak

Periode 2001-2010

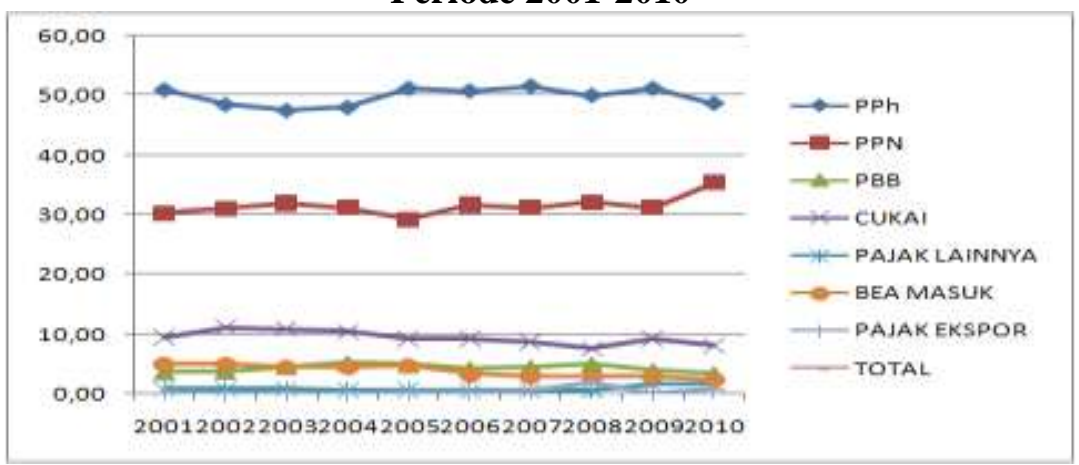

Sumber : Kementerian Keuangan Republik Indonesia (2011)

Salah satu faktor yang diperkirakan menjadi penyebab belum maksimalnya penerimaan pajak di Indonesia adalah masih rendahnya kepatuhan pajak (tax compliance). Rendahnya kepatuhan pajak ditandai dengan bentuk penggelapan pajak oleh wajib pajak (tax evasion). Penggelapan pajak dapat berupa penggelapan oleh wajib pajak terdaftar yang melaporkan pendapatan lebih rendah dari seharusnya maupun kegiatan yang tidak terdaftar resmi atau perekonomian tersembunyi (underground economy).

Kajian dan analisis mengenai pengaruh faktor ekonomi terhadap kepatuhan pajak ataupun penggelapan pajak telah banyak dilakukan, yang pertama kali dilakukan oleh Becker (1968) dengan memperkenalkan pendekatan teori ekonomi kriminal atau economics of crime, dimana individu diasumsikan akan memaksimasi utilitas-ekspektasinya melalui suatu permainan penghindaran pajak dengan melakukan under-reporting. Jumlah penghasilan yang digelapkan tergantung pada probabilitas audit dan besarnya denda. Selanjutnya dikembangkan oleh Allingham dan Sandmo (1972) yang dikenal dengan model A-S, di mana pembayar pajak diasumsikan sebagai pihak yang benar-benar tidak bermoral yang menyamakan keputusan apakah melakukan penggelapan pajak atau tidak, dan berapa banyak, dengan pendekatan keputusan beresiko yaitu sebagai suatu pilihan memaksimalkan utilitas yang diekspektasi.

Masalah penggelapan pajak di Indonesia merupakan suatu fenomena terkait dengan sistem perpajakan dan moral pajak. Sistem perpajakan seperti: tarip pajak, probabilitas audit, dan sanksi, secara teoritis merupakan salah satu sumber penyebab rendahnya kepatuhan pajak. Tarif pajak merupakan variabel yang sering menjadi obyek kebijakan, namun pemahaman terhadap permasalahan bagaimana perubahan tarif pajak mempengaruhi kepatuhan pajak masih terbatas. Pemeriksaan pajak merupakan salah satu instrumen yang baik untuk meningkatkan tingkat kepatuhan wajib pajak, baik formal maupun material dari peraturan perpajakan, yang tujuan utamanya untuk menguji dan meningkatkan kepatuhan perpajakan seorang wajib pajak.

Pandangan mengenai pentingnya peranan faktor-faktor tersebut di atas memotivasi peneliti untuk memfokuskan penelitian ini pada faktor-faktor yang menjelaskan perilaku kepatuhan para wajib pajak. Faktorfaktor ekonomi yang dianggap mempengaruhi kepatuhan pajak yaitu : tarif pajak, probabilitas audit dan penalti/ denda.

Berdasarkan uraikan di atas, maka informasi mengenai penyebab dalam penelitian ketidakpatuhan wajib pajak merupakan hal yang penting untuk meramu kebijakan yang dapat mempengaruhi perilaku wajib pajak perseorangan untuk menaati aturan pajak yang berlaku dalam rangka meningkatkan penerimaan pajak yang sangat dibutuhkan negara dalam rangka membangun, meningkatkan pelayanan publik, dan menutup defisit anggaran. Oleh sebab itu, kajian mendalam terhadap penyebab ketidakpatuhan wajib pajak sangat diperlukan agar informasi yang dihasilkan dapat menuntun pada para pengambil keputusan yang tepat bagi pihak yang terkait dengan upaya peningkatan kepatuhan pajak.

\section{TINJAUAN TEORITIS}

\subsection{Ulasan tentang Kepatuhan Pajak}

Kepatuhan pajak (tax compliance) adalah wajib pajak mempunyai kesediaan untuk memenuhi kewajiban pajaknya sesuai dengan aturan yang berlaku tanpa perlu diadakannya pemeriksaan, investigasi seksama, peringatan, atau pun ancaman dan penerapan sanksi baik hukum maupun administrasi (Gunadi, 2005).

Penggelapan pajak merupakan suatu isu penting untuk berbagai alasan sebagaimana berikut ini: (1) penggelapan pajak mengurangi pendapatan pajak terkumpul yang pada gilirannya mempengaruhi pajak yang 
dibayar oleh pembayar pajak yang patuh dan pelayanan publik yang diterima masyarakat; (2) penggelapan pajak menciptakan kesalahan alokasi sumberdaya manakala individu mengubah perilakunya dengan melakukan kecurangan pajak; (3) penggelapan pajak menimbulkan perasaan perlakuan tidak adil dan tidak menghargai aturan; (4) penggelapan pajak mempengaruhi keakuratan statistik makroekonomi (Alm,1993); (5) mengurangi efisiensi karena menciptakan kerugian (deadweight losses) atas perekonomian; (6) dapat menggeser pihak penanggung pajak (Andreoni et al., 1998).

\subsection{Beberapa Teori dan Model tentang Kepatuhan Pajak \\ 2.2.1. Teori Rasionalitas}

Salah satu pertimbangan kepatuhan pajak didasarkan pada pertimbangan ekonomi atas manfaat-biaya yang diekspektasi. Teori rasional berasumsi bahwa setiap manusia pada dasarnya rasional dengan selalu mempertimbangkan prinsip efesiensi dan efektivitas dalam melakukan setiap tindakan. Alfrad Marshall (18421924), menyatakan bahwa manusia selalu cenderung memaksimalkan rasionalitasnya, selalu cendrung menghitung nilai sesuatu (utility) yang hendak dipertukarkan. Adam Smith berpendapat bahwa perilaku manusia dituntun oleh rasionalitas instrumental yang terkait dengan kepentingan pribadi (self-interest) dan ditarik oleh prospek imbalan.

Tindakan rasional terkait dengan hasil. Rasionalitas mengatakan, jika kita ingin mencapai Y, lakukanlah X. Pada dasarnya rasionalitas bersyarat dan berorientasi masa depan (Elster,1989). Dalam kaitan dengan kepatuhan pajak, rasionalitas yang merupakan landasan dalam teori ekonomi dalam menghasilkan keputusan apakah menaati aturan perpajakan atau tidak.

\subsubsection{Teori Utilitas Ekspektasi (Expected Utility Theory): Model Allingham - Sandmo dan Pengembangannya.}

Model pendekatan penggelapan pajak oleh Allingham dan Sandmo (Model A-S, 1972) yang menggunakan konsep expected utility untuk menjelaskan perilaku kepatuhan wajib pajak. Mereka menggunakan variabel-variabel yang dikenal sebagai faktor ekonomi, yaitu: penghasilan sebelum pajak, tarif pajak, besarnya peluang untuk diperiksa dan besarnya penalti. Keputusan melaporkan pajak merupakan suatu keputusan dalam ketidakpastian sebab tidak melapor pendapatan secara penuh tidak secara otomatis mendapat penalti. Wajib pajak dapat memilih untuk melaporkan semua pendapatan aktualnya atau melaporkan dengan jumlah lebih sedikit. Keputusan mengenai jumlah pendapatan yang dilaporkan tergantung pada utilitas ekspektasi wajib pajak. Utilitas ekspektasi dianggap dapat dihitung (cardinal) yang merupakan utilitas tertimbang dari kegiatan melaporkan seluruh pendapatan dan melaporkan sebagian pendapatan dengan risiko terkena penalti. Keputusan kepatuhan pajak dalam model A-S adalah menentukan jumlah pendapatan yang akan dilaporkan agar dapat memaksimalkan utilitas ekspektasinya pada tataran perilaku penghindar risiko.

Yitzhaki (1974) memodifikasi model klasik dasar ini dengan memfokuskan pada dampak substitusi (subsitution effect) dari penalti. Argumen yang digunakan, yaitu jika tarif penalti berhubungan secara proporsional dengan tarif pajak, maka dampak subtitusi dapat dihilangkan, yang ada hanyalah dampak pendapatan. Dengan demikian, tidak terjadi ambigu. Di samping Yitzhaki, terdapat beberapa peneliti lain yang memodifikasi model A-S, seperti Slemrod et al. (1999), Orviska dan Hudson (2002), Chang dan Jin (2003), Snow dan Warren Jr. (2005), serta Eide (2002).

\subsubsection{Teori Moral Pajak}

Teori moral pajak menurut Frey dalam Simajuntak dan Mukhlis (2012) adalah motivasi intrinsik individu untuk bertindak, yang didasari oleh nilai-nilai yang dipengaruhi oleh norma-norma budaya. Prinsipprinsip moral atau nilai-nilai yang diyakini seseorang mengapa membayar pajak. Beberapa faktor yang mempengaruhi moral pajak seperti: persepsi adanya kejujuran, sikap membantu atau melayani dari petugas pajak, kepercayaan terhadap instansi pemerintah, penghargaan atau rasa hormat dari aparat pajak (respect), dan sifat-sifat individu lainnya.

Teori ini dengan pendekatan psikologi masyarakat, berpandangan bahwa antara masyarakat dan pemerintah terdapat kontrak implisit, yang mana masyarakat menyadari bahwa mereka memiliki hak dan kewajiban. Kebajikan warga negara akan muncul sebagai akibat hak-hak partisipasi masyarakat secara kolektif 
dihormati. Misalnya perlakuan jujur aparat berwenang, akan direspons masyarakat secara positif, sistem pajak dan pelayanan administrasi pajak yang baik membuat masyarakat puas dan menjadi faktor pendorong wajib pajak meningkatkan kepatuhannya (Simajuntak dan Mukhlis, 2012).

\subsection{Faktor-Faktor yang Mempengaruhi Kepatuhan Pajak}

\subsubsection{Hubungan Tarif Pajak dengan Kepatuhan Pajak}

Dalam kurva Laffer (Arthur Laffer 1980-an) terdapat dua titik ekstrim tarif (rate) pajak, yaitu pada titik ekstrim tingkat tarif pajak $0 \%$ di mana pendapatan pemerintah dari pajak akan nihil, dan pada pada titik ekstrim kedua yaitu tingkat tarif pajak $100 \%$, maka pendapatan pemerintah juga akan mendekati nihil, karena warga negara tidak akan mau membayar pajak entah dengan tidak bekerja atau tetap bekerja dengan cara lain untuk menghindari pajak baik halal atau haram. Tarif pajak yang optimum dari segi penerimaan negara berada si tengah-tengah rate $0 \%$ dan $100 \%$, (http://maskokilima.wordpress.com/2008/11/04/taxrate-complience-andlaffer-curve/).

Pada tataran teori sebagaimana model A-S yang dimodifikasi oleh Yitzhaki (1974), tarip pajak dianggap mempengaruhi secara negatif terhadap kepatuhan pajak, yaitu semakin besar tarif pajak, penggelapan pajak semakin menguntungkan. Hal ini didukung oleh beberapa temuan empirik yang memperlihatkan penurunan kepatuhan pajak seiring meningkatnya tarif pajak (Clotfelter,1983; Alm, Jackson, McKee, 1992; Chang dan Jin, 2003).

Hasil penelitian empiris lain menemukan hasil yang berbeda hubungan antara tarif pajak dengan kepatuhan pajak, seperti Feinstein 1991; Andreoni et al.,1998 menemukan hubungan positif antara tarif pajak dengan kepatuhan pajak. Begitu juga penelitian yang dilakukan oleh Alm, Sanchez, De Juan, (1995) menyatakan bahwa tarif pajak yang tinggi meningkatkan kepatuhan pajak. Hal ini sejalan prediksi model A-S, tetapi kontras dengan temuan-temuan empirik lainnya.

\subsubsection{Hubungan Probabilitas Audit dan Besarnya Denda dengan Kepatuhan Pajak}

Model A-S menekankan pada faktor audit dan penalti sebagai penghalang penggelapan pajak, namun kepatuhan pajak sering tidak dapat dijelaskan secara menyeluruh oleh faktor penghalang tersebut (Graetz dan Wilde, 1985). Collin dan Plumlee (1991) menemukan bahwa skema audit yang mengikutkan sinyal informasi awal yang dikirim kepada wajib pajak dapat sukses mengekang penggelapan pajak dibanding model audit acak murni.

Penggunaan probabilitas audit yang besar, bisa mengurangi penggelapan pajak. Namun demikian, besaran probabilitas audit sangat subyektif karena otoritas pajak tidak memiliki insentif untuk melakukan keseluruhan mekanisme audit (Alm, 1988). Pendapat ini timbul sebab dari sudut pandang ekonomi, upaya audit yang terlalu besar dapat meningkatkan inefisiensi karena akan memperbesar ukuran institusi pajak. Begitu juga, hasil studi dari Alm, Jackson, McKee, (1992), menunjukkan bahwa pelaporan wajib pajak meningkat seiring dengan semakin besarnya probabilitas audit dan penalti. Selanjutnya Asnawi et al. (2009), mengungkapkan bahwa untuk meningkatkan kepatuhan pajak, pemerintah tidak hanya memperhatikan faktor-faktor ekonomi seperti strategi audit dan perceived probability of audit tetapi juga perlu mempertimbangkan faktor psikologis seperti pemahaman etika pajak. Pemahaman etika pajak memiliki pengaruh yang dominan dalam peningkatan keputusan kepatuhan pajak dibandingkan faktor ekonomi (strategi audit random dan perceived probability of audit).

Namun Andreoni et al. (1998) berpendapat sebaliknya, dimana dengan sistem perpajakan yang modern, tingkat kepatuhan pajak tinggi meskipun probabilitas pemeriksaan pajaknya rendah dan sanksi pajaknya ringan. Dari pendapat mereka juga, menyebutkan ada aspek penting yang terlewatkan berdasarkan pengalaman nyata dalam dunia pelaporan pajak, yaitu aspek non ekonomi.

\subsubsection{Sanksi Pajak Bagi Wajib Pajak di Indonesia}

Sanksi pajak bagi wajib pajak yang berlaku saat ini berdasarkan UU No. 28 tahun 2007 tentang "Ketentuan Umum dan Tata Cara Perpajakan (KUP)". Ketentuan umum dan tata cara perpajakan di Indonesia mengatur sanksi bagi wajib pajak dalam bentuk sanksi denda dan sanksi pidana.

Namun demikian, tindak pidana di bidang perpajakan tidak dapat dituntut setelah lampau waktu sepuluh tahun sejak saat terhutangnya pajak, berakhirnya masa pajak, berakhirnya bagian tahun pajak, atau berakhirnya tahun pajak yang bersangkutan. 


\section{PENGEMBANGAN HIPOTESA}

Teori utilitas ekspektasi merupakan suatu pendekatan yang dilandasi pada motif ekonomi dengan asumsi yang mendasari bahwa manusia sebagai makhluk logis akan selalu bertindak berdasarkan pertimbangan untuk mendapatkan utilitas yang maksimal dari sumber daya yang dimilikinya. Berdasarkan konsep expected utility, seorang wajib pajak akan melaporkan penghasilannya sedemikian rupa sehingga tingkat expected utility dari penghasilan yang diterimanya akan maksimal. Model ini juga, menjelaskan bahwa wajib pajak adalah penghindar risiko (risk averser), yaitu wajib pajak akan mengambil risiko jika dan hanya jika utilitas yang diterima melebihi utilitas rata rata tertimbang berdasarkan risiko. Tingkat kepatuhan seharusnya meningkat seiring dengan peningkatan tarif pajak. Intuisi yang mendasari prediksi ini adalah bahwa dalam penggelapan pajak apabila laporan penghasilan teraudit, maka menjadi lebih berisiko ketika tarif pajak meningkat (Allingham dan Sandmo,1972)

Dalam model A-S juga, wajib pajak akan berusaha memaksimalkan expected utility dengan mempertimbangkan kondisi-kondisi yang dihadapi oleh wajib pajak, seperti kondisi kemungkinan wajib pajak akan diperiksa oleh fiskus. Kemungkinan wajib pajak akan diperiksa ditentukan oleh seberapa luas cakupan pemeriksaan yang dilakukan oleh fiskus. Dengan demikian, semakin tinggi cakupan pemeriksaan pajak, semakin tinggi kemungkinan wajib pajak akan diperiksa. Apabila audit rate tinggi, wajib pajak akan cenderung melaporkan sebagian besar dari penghasilannya ke fiskus. Berdasarkan teori expected utility, semakin besar probabilitas diperiksa dan faktor lain tetap, utility dari penghasilan yang tidak dilaporkan akan turun. Di pihak lain, utility penghasilan yang dilaporkan akan semakin tinggi.

Beberapa penelitian yang telah dilakukan tentang pengaruh probabilitas audit dan penalti denda terhadap kepatuhan pajak menjelaskan bahwa semakin tinggi tingkat pemeriksaan pajak dan denda/pinalti semakin tinggi, maka tingkat kepatuhan pajak semakin tinggi juga (Alm et.al. 1992, Asnawi et al.,2009), audit pajak dan tarip penalti penting untuk menghalangi penggelapan pajak meskipun tarip penalti lebih efektif (Chang dan Hyun 2003).

Kebijakan pemeriksaan jika diterapkan oleh fiskus mampu membentuk persepsi di kalangan wajib pajak bahwa kemungkinan besar wajib pajak akan diperiksa adalah tinggi, dan penalti yang akan dikenakan terhadap penghasilan yang tidak dilaporkan dianggap berat oleh wajib pajak. Dengan demikian berdasarkan konsep wajib pajak adalah rasional dan teori utility, maka dengan tingginya kemungkinan terdeteksinya penghasilan yang tidak dilaporkan dan besarnya penalti yang akan ditanggung wajib pajak menyebabkan utility penghasilan yang tidak dilaporkan wajib pajak menjadi rendah. Hal ini membuat wajib pajak dengan tarif efektif yang tinggi cenderung untuk patuh.

Berdasarkan pandangan tersebut, maka hipotesis faktor-faktor ekonomi yang mempengaruhi kepatuhan pajak dari penelitian ini adalah :

$\mathrm{H}_{1}$ : Tarif pajak berpengaruh positif terhadap kepatuhan pajak penghasilan.

$\mathrm{H}_{2}$ : Probabilitas audit berpengaruh positif terhadap kepatuhan pajak penghasilan

\section{METODE PENELITIAN}

Data dalam penelitian ini diperoleh melalui eksperimen, dimana pesertanya adalah mahasiswa Program Magister akuntansi dan Pendididikan Profesi Akuntansi Universitas Sam Ratulangi Manado. Eksperimen ini didasarkan pada teori keputusan sebab keputusan kepatuhan pajak adalah keputusan dalam ketidakpastian dan berisiko. Bentuk eksperimen adalah desain faktorial $3^{3}(3 \times 3 \times 3)$ di mana pada tiap tahapan terdapat keputusan yang diambil oleh partisipan/peserta, yaitu keputusan mengenai jumlah pendapatan yang akan dilaporkan, merupakan keputusan berisiko sebab peserta mengetahui besarnya probabilitas teraudit dan penalti/ denda.

Tahap pelaksanaan eksperimen peserta diminta untuk mengisi formulir manipulation check. Saat eksperimen, peserta diberi pendapatan laboratorium untuk tiap tahapan. Tarif penalti/denda sebesar $200 \%$ atas pajak yang digelapkan. Peserta diminta untuk melaporkan penghasilannya pada 
setiap tahapan, setelah itu proses audit pajak dilakukan. Penentuan peserta teraudit dilakukan secara acak dengan prosentase probabilitas sesuai treatment.

Ganjaran dihitung pada setiap tahap dan diinformasikan kepada tiap peserta sebagai umpan balik. Pada akhir kegiatan semi eksperimen, pengatur menghitung ganjaran total tiap peserta. Ganjaran sesungguhnya yang akan diterima peserta tergantung pada ganjaran semi eksperimen mereka. Pengaitan ini dimaksudkan untuk mendorong peserta agar bertindak seperti wajib pajak sesungguhnya.

Model analisis yang digunakan dalam penelitian ini adalah model persamaan regresi. Model persamaan regresi ini mengasumsikan bahwa penyelesaian masalah optimisasi wajib pajak perseorangan dapat dilinierisasi sebagaimana berikut ini:

$$
\begin{gathered}
K P J_{i}=\beta_{0}+\beta_{1} T P J_{i}+\beta_{2} P A_{i i}+\varepsilon_{i} \ldots \ldots . . .(1) \\
\text { di mana } \beta^{\prime}=\left[\beta_{0}, \beta_{1}, \beta_{2}\right] \text { dan } \\
x_{\mathrm{i}}=\left[1, \mathrm{TPJ}_{\mathrm{i}} \cdot \mathrm{PA} \mathrm{A}_{\mathrm{i}}\right] \text {, dan } \varepsilon \text { adalah residual. } \\
\text { Penjelasan atas notasi variabel adalah sebagai berikut. } \\
\text { KPJ }=\text { Kepatuhan pajak } \\
\text { TPJ= Tarif Pajak } \\
\text { PA } \quad=\text { Probabilitas Audit }
\end{gathered}
$$

Estimasi atas persamaan di atas menggunakan model Tobit sensor normal (Normal censored Tobit). Model penelitian ini menggunakan skema rasio kepatuhan, yaitu $y_{\mathrm{i}}=K P J_{i}$, Jika $0<\mathrm{KPJ}_{\mathrm{i}}<1$; dimana $y_{\mathrm{i}}$ adalah variabel dependen yang diobservasi ( Chang dan Jin, 2003).

\section{HASIL PENELITIAN DAN PEMBAHASAN}

Temuan-temuan penelitian ini mendukung prediksi dari hipotesa dan model yang dibangun. Rincian temuan-temuan tersebut adalah sebagai berikut.

1. Hasil temuan memperlihatkan bahwa tarif pajak berpengaruh positif terhadap perilaku kepatuhan pajak. Namun interaksi perubahan tingkat tarif pajak tidak ada perbedaan pengaruh terhadap tingkat kepatuhan pajak, maka situasi ini perlu diperhatikan karena memberikan pengaruh ambigu faktor tarif pajak terhadap kepatuhan pajak. Di satu pihak, peningkatan tarif pajak akan menjadi beban bagi wajib pajak, karena pajak dianggap biaya atau beban pajak penghasilan yang mengurangi bagian penghasilan yang akan diterima wajib pajak (Taxpayers). Semakin besar tarif pajak maka semakin tinggi biayanya atau semakin rendah penghasilan yang akan diterima (take home pay) bagi wajib pajak. Tetapi di lain pihak, peran positif tarif pajak dalam penelitian ini, karena wajib pajak dalam mengambil keputusan membayar pajak selain faktor tarif pajak ada juga faktor-faktor lain yang perlu dipertimbangkan, yaitu faktor probabilitas audit dan pelayanan pajak. Wajib pajak akan mempertimbangkan resiko yang mungkin timbul akibat penggelapan pajak, terutama jika penggelapan teraudit, maka ada denda yang harus dibayarkan .

2. Penelitian ini mengindikasikan peran positif probabilitas audit terhadap perilaku kepatuhan pajak. Peran positif tersebut dapat dilihat interaksi perubahan tingkat probabilitas audit menunjukkan terdapat perbedaan tingkat kepatuhan.Hal ini berarti apabila probabilitas audit ditingkatkan, maka wajib pajak akan terdorong untuk lebih patuh.

Semakin tinggi tingkat probabilitas audit dapat mempengaruhi psikologis wajib pajak, antara lain (1) ketakutan wajib pajak bila teraudit dan ada penggelapan pajak, (2) wajib pajak semakin respek terhadap institusi pajak bila semakin banyak pemeriksaan, (3) dengan sanksi bagi wajib pajak yang berlaku di Indonesia berupa denda dan/atau pidana yang cukup berat, maka perlu diperhatikan oleh institusi pajak kebijakan tentang peningkatan pemeriksaan. 


\section{PENUTUP}

\subsection{Kesimpulan}

Berdasarkan hasil penelitian dan pembahasan yang telah diuraikan sebelumnya, maka hasil penelitian ini dapat disimpulkan sebagai berikut.

1. Pengaruh tarif pajak terhadap kepatuhan pajak penghasilan orang pribadi menunjukkan adanya hubungan positif. Temuan ini sesuai dengan konsep wajib pajak adalah rasional dan teori utility, maka dengan tingginya kemungkinan terdeteksinya penghasilan yang tidak dilaporkan dan besarnya penalti yang akan ditanggung wajib pajak menyebabkan utility penghasilan yang tidak dilaporkan wajib pajak menjadi rendah. Hal ini membuat wajib pajak dengan tarif efektif yang tinggi cenderung untuk patuh. Tetapi untuk perubahan tingkat tarif pajak tidak terdapat perbedaan pengaruh terhadap kepatuhan pajak. Situasi ini memberikan pengaruh ambigu faktor tarif pajak terhadap kepatuhan pajak, apabila tarif pajak tinggi, maka wajib pajak menganggap pajak merupakan biaya yang mengurangi bagian penghasilan yang akan diterimanya.

2. Probabilitas audit berpengaruh positif terhadap kepatuhan pajak penghasilan. Perubahan tingkat probabilitas audit terdapat perbedaan pengaruh terhadap kepatuhan pajak, bahwa semakin besar kemungkinan diperiksa wajib pajak oleh fiskus, maka semakin patuh para wajib pajak, hal ini dapat dilihat pada pengalaman yang diperoleh wajib pajak saat laporan penghasilannya teraudit, cenderung meningkatkan kepatuhan pajak mereka pada periode pelaporan berikutnya.

\subsection{SARAN}

Berdasarkan temuan-temuan empirik yang diperoleh dalam penelitian ini, maka beberapa saran akan dikemukakan sebagai berikut.

1. Bagi pemerintah sebagai pengambil keputusan, perlu menentukan tingkat tarif pajak yang dapat menjangkau seluruh lapisan penghasilan kena pajak, karena besaran tarif pajak sangat berpengaruh terhadap perilaku taxpayers terhadap aturan pajak (honest) atau tidak (evades). Walaupun dalam temuan penelitian ini tarif pajak berpengaruh positif terhadap kepatuhan wajib pajak, Namun bukan berarti tarif pajak dapat dinaikan lagi, karena penentuan tingkat tarif pajak harus berada pada suatu tingkat yang optimum dimana para warga negara sebagai wajib pajak mampu membayarnya.

2. Institusi pajak hendaknya melakukan fokus pemeriksaan kepada wajib pajak yang berusaha menghindari dan menggelapkan pajak. Selain itu, perlu dilakukan pembenahan terhadap kebijakan sanksi dan denda, sehingga meminimalisasikan peluang menghindari dan mengelapkan pajak. Demikian juga dengan penegakan hukum, karena tidak sepenuhnya kebijakan audit, denda/sanksi bisa sepenuhnya menjamin wajib pajak akan mematuhi seluruh kewajibannya, jika tidak didukung dengan penegakan hukum. Penegakan hukum harus memberikan rasa keadilan dan efek jera kepada wajib pajak, agar di dalam masyarakat apabila wajib pajak tidak patuh akan merasa takut terhadap hukum dan sebaliknya, bagi wajib pajak yang patuh ada rasa bangga atau mendapat penghargaan.

3. Pemerintah perlu menunjukkan tindakan-tindakan yang nyata terhadap wajib pajak bahwa perilaku aparat pajak dapat menjamin kepercayaan institusi yang bersih dan berwibawa, transparansi penggunaan dan alokasi sumber penerimaan pajak, menekan tindakan manipulasi pajak, serta meningkatkan tindakan penegakan hukum (law enforcement) kepada aparat pajak yang tidak jujur.

\section{DAFTAR PUSTAKA}

Allingham, M., and A. Sandmo (1972), "Income Tax Evasion: A Theoretical Analysis," Journal of Public Economics, 1: 323-338.

Alm, J. (1993), “Tax Evasion,” http://www.urban.org/pubs/taxation/alm.html. 
Alm, J. (1988), "Uncertainty Tax Policies, Individual Behavior, and Welfare," American Economic Review, 78: $237-245$.

Alm, J. (1998), “Tax compliance and Administration, ” Working Paper University of Colorado at Boulder, 98-12

Alm, J., Jackson B.R., and M. McKee (1992), "Estimating The Determinants of Taxplayer With Experimental Data ," National Tax Journal, Vol.45 No.1 (March 1992), pp 107-114.

Alm, J., I. Sanchez, and A. De Juan (1995), "Economic and Noneconomic Factors in Tax Compliance," Kyklos, 48: $1-18$.

Alm, J. and B. Torgler (2005), "Culture Differences and Tax Morale in the United States and in Europe," Journal of Economic Psychology, xxx: 1-23.

Andreoni, J., B. Erard, and J. Feinstein (1998), “Tax Compliance,” Journal of Economic Literature, XXXVI: 818-860.

Asnawi, Meinarni SE.M.Si.,Prof.Dr. Zaki Baridwan, Dr. Supriyadi. M.Sc., Dr. Ertambang, M.Sc. (2009), "Analisis Keputusan Kepatuhan Pajak: Strategi Audit Random, Perceived Probability Of Audit Dan Pemahaman Etika Pajak(Studi Eksperimen Laboratorium)", Simposium Nasional Akuntansi XII.Palembang.

Becker, G. S. (1968), "Crime and Punishment: an Economic Approach," Journal of Political Economy, 76: 169-217.

Bird, R.. M., and E. M. Zolt (2005), "The Limited Role of the Personal Income Tax in Developing Countries," Journal of Asian Economics, 16: 928-946.

Brooks, N. (2001), "Key Issues in Income Tax: Challenges of Tax Administration and Compliance", Asian Development Bank 2001 Tax Conference, Tokyo.

Chang-Gyun P., and Jin. K. Hyun (2003), "Examining the Determinants of Tax Compliance by Experimental Data: A Case of Korea," Journal of Policy Modeling, 25: 673-684.

Chattopadhyay, S., and A. Das-Gupta (2002), "The Personal Income Tax in India: Compliance Costs and Compliance Behavior Taxpayers," National Institute of Public Finance and Policy, New Dehli.

Clotfelter, C. (1983), "Tax Evasion and Tax Rates: An Analysis of Individual Return," The Review of Economics and Statistics, 65(3): 363-373.

Collin, J. H., and R. D. Plumlee (1991), "The Taxpayer's Labor and Reporting Decision: The Effect of Audit Schemes," The Accounting Review, 66 (3): 559-576.

Cooper, D. R., and P. S. Schindler (2006), Business Research Method, $9^{\text {th }}$ ed., The McGraw-Hill/Irwin, Boston.

Cummings, R.G. et al. (2005), "Effects of Culture on Tax Compliance: A Cross Check of Experimental and Survey Evidence," Working Paper CREMA, 2005-29

Eide E.(2002) "Tax Evasion with Rank Dependent Expected Utility", Paper Submitted for Presentation to the $9^{\text {th }}$ Annual Conference of the European Association of Law and Eand Economics, Athens, September, 2002, 19-21.

Feinstein, J. S. (1991), "An Econometric Analysis of Income Tax Evasion and Its Detection," RAND Journal of Economics, 22: 14-35.

Feld, L. P., and B. S. Frey (2002), "Deterrence and tax Morale: How Tax Administrations and Taxpayers Interact," OECD Jan Francke Tax Research Award.

Feld, L.,P \& Frey, B. (2006), "Tax evasion in Switzerland: The role of deterrence and tax morale”, Working paper No 284, Institute for Empirical Research in Economics, University of Zurich.

Feld, L.,P \& Frey, B. (2007), "Tax Compliance as the Result of a Psychological Tax Contract: The Role of Incentives and Responsive Regulation", Law \& Policy, Vol. 29, No. 1, January 2007.

Forest, A., and S. M. Sheffrin (2002), "Complexity and Compliance: An Empirical Investigation," National Tax Journal, LV (1): 75-88.

Graetz, M. J., and L. L. Wilde (1985), "The Economics of Tax Compliance: Fact and Fantasy," National Tax Journal, 38: 355-363.

Gunadi, (2005), "Fungsi Pemeriksaan Terhadap Peningkatan Kepatuhan Pajak (Tax Compliance)". JurnalPerpajakan Indonesia Vol.4 no.5.

Gujarati, D. M. (2003), Basic Econometrics, $4^{\text {th }}$ ed., McGraw Hill, Boston

Jatmiko, Agus Nugroho ((2006), "Pengaruh Sikap Wajib Pajak pada Pelaksanaan Sanksi Denda, Pelayanan Fiskus dan Kesadaran Perpajakan Terhadap Kepatuhan Wajib Pajak (Studi Empiris Terhadap Wajib Pajak Orang Pribadi di Kota Semarang)", eprints.undip.ac.id/15261/1/Agus_Nugroho_Jatmiko.pdf. Diakses pada tanggal 1 April 2012

Kamus Besar Bahasa Indonesia, 2005, Edisi Ketiga, Pusat Bahasa Departemen Pendidikan Nasional, Balai Pustaka, Jakarta.

Mustikasari, Elia (2007), “ Kajian Empiris Tentang Kepatuhan Wajib Pajak Badan di Perusahaan Industri Pengolahan di Surabaya" Simposium Nasional Akuntansi X. Makassar. 
Organization for Economic and Coorporation Development-OECD, (2001), "Compliance Measurement Practice" Note: 1- 23. 2001.

Orviska, M., and J. Hudson (2002), “Tax Evasion, Civic Duty, and the Law Abiding Citizen,” European Journal of Political Economy, 19: 83-32.

Poputra, A.T. (2009), "Ketaatan Pajak Penghasilan Di Indonesia, Disertasi pada Universitas Gadjah Mada, Yogyakarta (belum dipublikasikan).

Sandmo, A. (2004), "The Theory of Tax Evasion: A Retroactive View," Paper for Nordic Workshop on Tax Policy and Public Economics in Helsinki.

Santoso, Wahyu (2008), “Analisis Risiko Ketidakpatuhan Wajib pajak Sebagai Dasar Peningkatan Kepatuhan Wajib Pajak (Penelitian terhadap Wajib Pajak Badan Di Indonesia)", Jurnal Keuangan Publik Vol. 5, No. 1, Hal 85 - 137, Oktober 2008

Simajuntak, T.H dan Mukhlis Imam (2012), “ Dimensi Ekonomi Perpajakan Dalam Pembangunan Ekonomi”, Penerbit Raih Asa Sukses, Jakarta.

Skinner, J., and J. Slemrod (1985), “An Economic Perspective on Tax Evasion,” National Tax Journal, 3: 345353

Slemrod, J., M. Blumenthal, and C. Christian (1999), "Taxpayer Response to an Increased Probability of Audit: Evidence from a Controlled Experiment in Minnesota, ” Journal of Public Economics, 79: 455-483.

Smith, A. (1776 [1965]), "An Inquiry into the Nature and Causes of the Wealth of Nations", Modern Library, New York.

Snow, A., and R. A. Warren Jr (2005), "Tax Evasion under Random Audits with Uncertain Detection," Economics Letters, 88: 97-30.

Subiyantoro, Heru dan Singgih Riphat (2004), "Kebijakan Fiskal Pemikiran,Konsep, dan Implementasi", Jakarta: Penerbit Buku Kompas.

Suryadi (2006), "Model Hubungan Kausal Kesadaran, Pelayanan, Kepatuhan Wajib Pajak dan Pengaruhnya Terhadap Kinerja Penerimaan Pajak di Wilayah Jawa Timur". Jurnal Keuangan Publik. Vol 4, No. 1, p 105-121.

Waluyo dan Wirawan (2008), "Perpajakan Indonesia", Salemba Empat, Edisi 8.

Wardiyanto Bintoro, 2010, "Kebijakan Pengampunan Pajak (Tax Amnesty): Perspektif Kerangka Kerja Implementasi Sunset Policy mendasarkan UU No 28 tahun 2007", Jurnal Masyarakat Kebudayaan dan Politik, Volume 21, Nomor 4:328-335.

Witte, A.D., and D.F. Woodburry (1985), "The effect of Tax Laws and Tax Administration on Tax Compliance," National Tax Journal, 38: 1-14.

William R. Yount (2006), "Research Design and Statistical Analysis in Christian Ministry”, 4th Edition, Copyright (C) 2006 Printed in the United States of America.

Wooldridge, J. (2003), "Introduction to Econometrics: A Modern Approach", $2^{\text {nd }}$ ed., Thomson Publishing, Ohio.

Yitzhaki, S. (1974), “A Note on Income Tax Evasion: A Theoretical Analysis,” Journal of Public Economics, 3 (2): 201-211.

Yitzhaki, S. (1987), “On the Excess Burden of Tax Evasion,” Public Finance Quarterly 15: 123-137.

Republik Indonesia, Undang-Undang No.36 tahun 2008 tentang Perubahan keempat atas UU No.7 tahun 1983 tentang Pajak Penghasilan .http://www.ortax.org/ortax Peraturan Perpajakan.

Republik Indonesia, Undang-Undang No.28 tahun 2007 tentang Ketentuan Umum dan Tata Cara Perpajakan (KUP). http://www.ortax.org/ortax Peraturan Perpajakan.

Republik Indonesia, Peraturan Menteri Keuangan Republik Indonesia Nomor 74/PMK.03/2012 Tentang Tata Cara Penetapan dan Pencaputan Penetapan Wajib Pajak dengan Kriteria Tertentu dalam rangka Pengembalian Pendahuluan Kelebihan Pembayaran Pajak.

Republik Indonesia, Surat Edaran Nomor SE-79/PJ/2010 Tentang Standard Operating Procedure (SOP) Layanan Unggulan Bidang Perpajakan.

http://chairuelamien.blogspot.com/2011/06/teori-rasionalitas-petani.html. Diakses pada tanggal 8 Desember 2011.

http://www.depkeu.go.id/ind. Diakses pada tanggal 29 Agustus 2012.

http://finance.detik.com/pemerintah serap29 agt 2012, detik.com 31 Mei 2011, diakses pada 29 Agustus 2012.

http://maskokilima.wordpress.com/2008/11/04/taxrate-complience-and-laffer-curve, diakses pada 22 Pebuari 2012 
http://www.pajak.go.id/content/article/berapa-sih-sebenarnya-tax-ratio- indonesia di akses pada 30 Agustus 2012

http://id.wikipedia org/wiki/Penghindaran Pajak. Diakses pada tanggal 8 Desember 2012

www.anggaran depkeu.go.id/dja/acontent/Data Pokok APBN 2013.pdf. Diakses pada tanggal 22 April 2013. 